\title{
Dietary and socio-economic factors associated with overweight and obesity in a southern French population
}

\author{
J Scali ${ }^{1}$, S Siari ${ }^{1}$, P Grosclaude ${ }^{2}$ and M Gerber ${ }^{1, *}$ \\ 'Groupe d'Epidémiologie Métabolique, Centre de Recherche en Cancérologie, INSERM-CRLC, \\ F-34298 Montpellier Cedex 5, France: ${ }^{2}$ Registre des Tumeurs du Tarn, Albi, Tarn, France
}

Submitted 28 April 2003: Accepted 3 September 2003

\begin{abstract}
Objective: To investigate the socio-economic and dietary factors associated with overweight and obesity, respectively, in southern France.

Design: Cross-sectional analysis of socio-economic, lifestyle and nutritional characteristics of a representative population sample. A questionnaire elicited information on anthropometric measurements, socio-economic factors, physical activity, tobacco use, and alcohol and food intakes. Non-parametric tests, multiple linear regression models and correspondence factorial analysis (CFA) were used to estimate the association of the various factors with overweight and obesity.

Setting: French Southwest and Mediterranean areas.

Subjects: In total, 1169 subjects (578 women and 552 men), aged 30-77 years, were recruited at random.

Results: Overweight and obesity were associated with age and education in both genders, reproductive factors in women and tobacco use in men. A few dietary factors were identified (high energy intake and low intake of carbohydrates), but all these variables explained little of the variation (18.5\% in women and $14.6 \%$ in men). The CFA further investigated the association of lifestyle and nutritional factors, giving more weight to nutritional behaviour for overweight men and women. Factors for obesity differed from those for overweight by being different in men and women, possibly related to psychological behaviour, and there were fewer of them, suggesting an insufficient coverage by the usual questionnaires.

Conclusions: Overweight and obesity appear as two different entities. Energy imbalance induced by various lifestyle factors plays a major role in the development of overweight, whereas obesity represents a more complex entity where psychological and genetic factors that are difficult to assess may be more important. General nutritional guidelines appear more adapted to the prevention of overweight than to that of obesity, and individual counselling to the prevention of obesity.
\end{abstract}

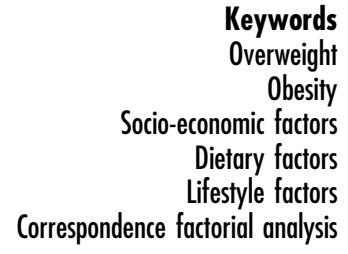

Keywords Oberight Obesity Dietary factors Lifestyle factors Correspondence factorial analysis

\begin{abstract}
Obesity has reached epidemic proportions in many countries of the Western world ${ }^{1}$. France has a proportion of overweight and obesity among the lowest for European countries $^{2,3}$. Within France, women from southern regions display the lowest percentage of overweight and obesity (F Clavel, personal communication). However, a recent report on the body mass index (BMI) of young army recruits showed that the prevalence of overweight and obesity was increasing more rapidly in individuals from the Mediterranean region ${ }^{4}$ compared with other French regions, thus opening a debate on the relevance of the Mediterranean diet as a nutritional model ${ }^{5}$. As obesity is strongly associated with the main causes of morbidity and mortality in the Western world - cardiovascular disease, cancer and diabetes $^{6,7}$, its reduction is a necessary health goal. Environmental determinants coupled with genetic susceptibility are the key factors contributing to a rise in
\end{abstract}

overweight and obesity, and a greater understanding of these factors would lead to the development of more appropriate health policies. In this study, conducted in French Mediterranean and Southwest regions, we focused on socio-economic and individual factors (diet and physical activity) and their potential relationship with overweight and obesity, respectively.

\section{Subjects and methods}

\section{Subjects}

The MEDHEA study (Mediterranean Diet and Health) ${ }^{8-11}$ randomly recruited 1521 subjects aged 20-77 years from electoral lists in Toulouse, Marseille and the Hérault and Tarn regions, between January 1994 and November 1996. Twenty-seven per cent of subjects responded to the letter 
sent inviting them to participate in the study, and $48 \%$ of these agreed to participate.

We selected 1169 subjects aged between 30 and 77 years, because the distribution of BMI by age showed few overweight (8.0\%) and obese (1.8\%) subjects below 30 years of age. Underreporters were identified as men declaring a daily intake $<6270 \mathrm{~kJ}$, and women $<5200 \mathrm{~kJ}$. However, because food-frequency questionnaires (FFQs) are known to underestimate energy intake and because aged sedentary subjects might live on low energy intake, reporting of these subjects was ultimately re-evaluated according to their physical activity in order to minimise exclusions. When energy expenditure related to physical activity, estimated according to Ainsworth et al. ${ }^{12}$, was not $>10 \%$ of energy intake, the subjects were re-integrated into the study sample. None of the excluded subjects was obese. The final sample was comprised 578 women and 552 men.

\section{Questionnaire}

The questionnaire elicited information on sociodemographic factors, anthropometric characteristics (selfdeclared) and food intake, estimated by frequency of consumption (ranging from twice a day to once per month). The 162 foods or food groups were quantified using a set of photographs. This quantitative FFQ has been validated by correlations of energy and macronutrient intakes (Pearson correlation coefficient from 0.65 for vitamin $\mathrm{E}$ to 0.37 for monounsaturated fatty acids, with 0.57 for energy $)^{13-15}$. Questions on occupational and leisure physical activity were included, organised as previously reported in the literature ${ }^{16-18}$. Subjects indicated their type of work, in which they were assumed to be engaged for $38 \mathrm{~h}$ per week (the usual weekly work period at that time; no subject declared part-time work), and the type of sport with time spent per week. Each activity was characterised by a score according to Ainsworth et $a l^{12}$ and a metabolic equivalent per day $\left(\right.$ MET day ${ }^{-1}$ ) calculated according to Falkner et al. ${ }^{19}$ for work physical activity and leisure physical activity as follows:

$$
\begin{aligned}
& \text { work physical activity }\left(\text { MET day }{ }^{-1}\right) \\
& =(\text { work MET score } \times 38) / 7
\end{aligned}
$$

and

$$
\begin{aligned}
& \text { leisure physical activity }\left(\text { MET day }{ }^{-1}\right) \\
& =(\text { leisure MET score } \times \text { time spent per session } \\
& \quad \times \text { number of sessions per week }) / 7 \text {. }
\end{aligned}
$$

\section{Statistics}

Missing data from $0.2 \%$ (alcoholic beverage intake) to $29 \%$ (use of oral contraceptives) of subjects were corrected to 0 to $0.6 \%$ using the cold-deck (comparison with similar studies on the same sample) and deductive (logical verification) methods ${ }^{20}$.

SAS version 8.2 (SAS Institute, Cary, NC, USA) was used for statistical analysis.

Chi-square tests were used to analyse differences in the distribution of age (two categories: $30-49$ years and $\geq 50$ years, selected after considering the distribution of BMI by 5-year age groups - overweight increased from 50 years and above in women and from 30 years and above in men; there was no such increase in obesity in both sexes), socioeconomic factors comprising education ( $<$ high school degree, $\geq$ high school degree), occupational activity (yes, no), occupational status (none, manual workers, whitecollar workers and executives, employees and blue-collar workers), marital status (single, couple) and smoking habits (never, current smoker, ex-smoker), and reproductive life-related variables for women, categorised according to their relevance to breast cancer risk (age at menarche (9-11 years, $12-13$ years, $14-17$ years); parity $(<3, \geq 3)$; menopausal status (yes, no); use of oral contraceptives (yes, no); and hormone replacement therapy (HRT) use (yes, no)), across normal weight $\left(<25 \mathrm{~kg} \mathrm{~m}^{-2}\right)$, overweight $\left(\geq 25\right.$ to $\left.<30 \mathrm{~kg} \mathrm{~m}^{-2}\right)$ and obese $\left(\geq 30 \mathrm{~kg} \mathrm{~m}^{-2}\right)$ BMI categories. Husband's occupational status was attributed to women without occupation in order to estimate their social status (but was not used for their physical activity estimation). Differences in median values of nutrient consumption and physical activity among the three BMI categories were analysed using the non-parametric Kruskal-Wallis test. Factors shown to be significantly associated with BMI, in at least one sex, were incorporated into a multiple linear regression analysis. Two models were tested, one introducing energy intake and the other replacing energy by the percentage of energy provided by each macronutrient.

To characterise the subjects in each BMI class, we used correspondence factorial analysis (CFA) using the correspondence analysis procedure in SAS. The subjects in each BMI category were analysed against energy and macronutrient intakes plus each variable shown to be significant in the univariate analysis. The association is expressed as the value of the distance on the axes and the proximity to the axes. Only distances on the axis $\geq 0.10$ were considered.

\section{Results}

Among the 578 women, 16.4\% were overweight and 6.4\% were obese. Among the 552 men, 41.5\% were overweight and $4.2 \%$ were obese. Table 1 shows that the distribution of the three BMI categories was significantly different across age, education, occupational activity and occupational status categories in the sample of women. The distribution of the three categories of BMI was also significantly different across categories of menopausal 
Table 1 Distribution of sociodemographic factors and smoking habits among normal-weight (body mass index (BMI) $<25 \mathrm{~kg} \mathrm{~m}^{-2}$ ), overweight (BMI $\geq 25$ to $<30 \mathrm{~kg} \mathrm{~m}^{-2}$ ) and obese $\left(\mathrm{BMI} \geq 30 \mathrm{~kg} \mathrm{~m}^{-2}\right.$ ) women

\begin{tabular}{|c|c|c|c|c|c|c|c|}
\hline \multirow[b]{2}{*}{ Factor } & \multicolumn{2}{|c|}{ Normal weight } & \multicolumn{2}{|c|}{ Overweight } & \multicolumn{2}{|c|}{ Obese } & \multirow[b]{2}{*}{$P$-value } \\
\hline & $n$ & $\%$ & $n$ & $\%$ & $n$ & $\%$ & \\
\hline \multicolumn{8}{|l|}{ Age (years) } \\
\hline $30-49$ & 253 & 87.8 & 21 & 7.3 & 14 & 4.9 & \\
\hline$\geq 50$ & 193 & 66.6 & 74 & 25.5 & 23 & 7.9 & $<0.001$ \\
\hline \multicolumn{8}{|l|}{ Occupational activity } \\
\hline Yes & 165 & 66.0 & 64 & 25.6 & 21 & 8.4 & \\
\hline $\mathrm{No}^{*}$ & 281 & 85.7 & 31 & 9.4 & 16 & 4.9 & $<0.001$ \\
\hline \multicolumn{8}{|l|}{ Occupational status } \\
\hline None & 42 & 67.7 & 13 & 21.0 & 8 & 12.9 & \\
\hline Manual workers & 12 & 52.2 & 10 & 43.5 & 1 & 11.7 & \\
\hline White-collar workers and executives & 180 & 83.3 & 24 & 11.1 & 12 & 5.5 & \\
\hline Employees and blue-collar workers & 212 & 76.8 & 48 & 17.4 & 16 & 5.8 & $<0.001$ \\
\hline \multicolumn{8}{|l|}{ Education } \\
\hline$<$ High school degree & 171 & 68.1 & 61 & 24.3 & 19 & 7.6 & \\
\hline$\geq$ High school degree & 274 & 84.0 & 34 & 10.4 & 18 & 5.5 & $<0.001$ \\
\hline \multicolumn{8}{|l|}{ Marital status } \\
\hline No & 102 & 15.3 & 20 & 15.3 & 9 & 6.9 & \\
\hline Yes & 344 & 16.8 & 75 & 16.8 & 28 & 6.3 & NS \\
\hline \multicolumn{8}{|l|}{ Smoking } \\
\hline Never & 269 & 74.9 & 69 & 19.2 & 21 & 5.8 & \\
\hline Current & 97 & 85.8 & 9 & 8.0 & 7 & 6.2 & \\
\hline Ex-smoker & 80 & 75.5 & 17 & 16.0 & 9 & 8.5 & NS \\
\hline \multicolumn{8}{|l|}{ Age at menarche (years) } \\
\hline $9-11$ & 77 & 67.0 & 25 & 21.7 & 13 & 11.3 & \\
\hline $12-13$ & 228 & 80.0 & 41 & 7.4 & 16 & 5.6 & \\
\hline $14-17$ & 139 & 79.0 & 29 & 16.5 & 8 & 4.5 & $<0.05$ \\
\hline \multicolumn{8}{|l|}{ Parity } \\
\hline$<3$ & 335 & 79.2 & 64 & 15.1 & 24 & 5.7 & \\
\hline$\geq 3$ & 111 & 71.6 & 31 & 20.0 & 13 & 8.4 & NS \\
\hline \multicolumn{8}{|l|}{ Menopausal status } \\
\hline Yes & 186 & 66.9 & 70 & 25.2 & 22 & 7.9 & \\
\hline No & 260 & 86.7 & 25 & 8.3 & 15 & 5.0 & $<0.0001$ \\
\hline \multicolumn{8}{|l|}{ Use of oral contraceptives } \\
\hline Yes & 290 & 85.5 & 37 & 10.9 & 12 & 3.5 & \\
\hline No & 156 & 65.3 & 58 & 24.3 & 25 & 10.5 & $<0.0001$ \\
\hline \multicolumn{8}{|l|}{ HRT use } \\
\hline Yes & 75 & 67.0 & 29 & 25.9 & 8 & 7.1 & \\
\hline No & 371 & 79.6 & 66 & 14.2 & 29 & 6.2 & $<0.01$ \\
\hline
\end{tabular}

HRT - hormone replacement therapy; NS - not significant.

${ }^{*}$ Retired or unemployed.

status, use of oral contraceptives and HRT use, as expected given the high level of correlation of these variables with age. With regard to age at menarche, which is independent of the age categories within the sample, a higher proportion of overweight and obesity was found in women with an early menarche.

BMI also increased with age and decreased with education level in the sample of men (Table 2). But the distribution of BMI in each age category was different between men and women, with more overweight in the younger men than in the younger women and more obesity in the older women than in the older men. The percentage of overweight and obese men was comparable among the categories of occupational activity and status, whereas it was significantly different among the categories of smoking and marital status, both factors showing no association with BMI in women.

Very few dietary variables were different among the three categories of BMI. There was no significant difference in energy consumption. In women the median energy intake was very close in the three BMI categories, around $7300 \mathrm{~kJ} \mathrm{day}^{-1}$, but the minima increased with BMI category whereas the maxima remained very close (3182.4-18509.3, 3513.8-17803.2 and 3760.2$17881.5 \mathrm{~kJ} \mathrm{day}^{-1}$ for normal-weight, overweight and obese women, respectively). Such a tendency was also observed for fat intake as measured in $\mathrm{g} \mathrm{day}^{-1}$. However, when expressed as a percentage of total energy intake, obese women declared the highest median consumption of saturated fatty acids (13.2, 12.2 and 13.6\%, respectively; $P=0.05)$ and polyunsaturated fatty acids (7.6, 8.1 and $9.1 \%$, respectively; $P<0.05$ ). Physical activity appeared to be lower in obese women, with a borderline significant lower activity at work $(P=0.08)$ and significantly less leisure-time physical activity $(P=0.02)$; the latter was nil in $46.7 \%$ of obese women.

In men as in women, there was no significant difference in energy consumption. However, obese men always declared slightly higher energy intake (median daily energy intake in normal-weight, overweight and obese 
Table 2 Distribution of sociodemographic factors and smoking habits among normal-weight (body mass index (BMI) $<25 \mathrm{~kg} \mathrm{~m}^{-2}$ ), overweight (BMI $\geq 25$ to $<30 \mathrm{~kg} \mathrm{~m}^{-2}$ ) and obese $\left(\mathrm{BMI} \geq 30 \mathrm{~kg} \mathrm{~m}^{-2}\right.$ ) men

\begin{tabular}{|c|c|c|c|c|c|c|c|}
\hline \multirow[b]{2}{*}{ Factor } & \multicolumn{2}{|c|}{ Normal weight } & \multicolumn{2}{|c|}{ Overweight } & \multicolumn{2}{|c|}{ Obese } & \multirow[b]{2}{*}{$P$-value } \\
\hline & $n$ & $\%$ & $n$ & $\%$ & $n$ & $\%$ & \\
\hline \multicolumn{8}{|l|}{ Age (years) } \\
\hline $30-49$ & 161 & 64.9 & 79 & 31.9 & 8 & 3.2 & \\
\hline$\geq 50$ & 139 & 45.8 & 150 & 49.3 & 15 & 4.9 & $<0.001$ \\
\hline \multicolumn{8}{|l|}{ Occupational activity } \\
\hline Yes & 101 & 48.1 & 98 & 46.7 & 11 & 5.2 & \\
\hline $\mathrm{No}^{*}$ & 199 & 58.2 & 131 & 38.3 & 12 & 3.5 & NS \\
\hline \multicolumn{8}{|l|}{ Education } \\
\hline$<$ High school degree & 129 & 48.0 & 124 & 46.1 & 16 & 5.9 & \\
\hline$\geq$ High school degree & 170 & 60.1 & 105 & 37.1 & 7 & 2.5 & $<0.01$ \\
\hline \multicolumn{8}{|l|}{ Occupational status } \\
\hline Manual workers & 37 & 48.7 & 34 & 44.7 & 5 & 6.6 & \\
\hline White-collar workers and executives & 109 & 56.1 & 78 & 40.2 & 7 & 3.6 & \\
\hline Employees and blue-collar workers & 150 & 54.1 & 116 & 41.9 & 11 & 4.0 & NS \\
\hline \multicolumn{8}{|l|}{ Marital status } \\
\hline No & 49 & 72.1 & 17 & 25.0 & 2 & 2.9 & \\
\hline Yes & 248 & 72.1 & 211 & 45.0 & 21 & 4.4 & $<0.01$ \\
\hline \multicolumn{8}{|l|}{ Smoking } \\
\hline Never & 118 & 60.5 & 72 & 36.9 & 5 & 2.6 & \\
\hline Current & 85 & 57.8 & 57 & 38.8 & 5 & 3.4 & \\
\hline Ex-smoker & 96 & 45.9 & 100 & 47.8 & 13 & 6.2 & $<0.05$ \\
\hline
\end{tabular}

NS - not significant.

${ }^{*}$ Retired or unemployed.

men: 9303, 9632 and $11523 \mathrm{~kJ}$, respectively) as well as higher intakes of total fat and specific fatty acids, expressed in $\mathrm{g} \mathrm{day}^{-1}$ or in percentage of total energy intake. Only carbohydrate intake showed a significant difference, with less contribution to total energy consumption in overweight and obese men than in men with a normal BMI (daily \% of total energy intake for normal-weight, overweight and obese men: 42.7, 41.3 and 40.2, respectively; $P<0.05$ ). Alcohol intake as an absolute amount (median for normal-weight, overweight and obese men: 11.6, 13.7 and $9.5 \mathrm{~g} \mathrm{day}^{-1}$, respectively; $P=0.05)$ as well as a percentage of energy (3.3, 4.2 and $2.9 \%$, respectively; $P<0.05$ ) was significantly lower in obese men and higher in overweight ones. There was no difference among men with regard to physical activity.

Whereas daily energy intake considered by sex did not appear to differ among the BMI categories, it was significantly higher in overweight subjects for the total sample (median (min-max): normal-weight, 8270 (3182$27703) \mathrm{kJ}$; overweight, 8935 (3514-28 592) kJ; obese, 8341 (3760-20512) kJ; $P<0.01)$.

The first multiple regression model for women included significant socio-economic factors, reproductive life-related factors and energy intake. Age was the strongest explanatory variable (10\%) followed by age at menarche, education level and use of oral contraceptives, adding up to $14.8 \%$. In model 2 , energy intake was replaced by the percentage of energy provided by each macronutrient. In this model, $R^{2}$ reached $18.5 \%$ as carbohydrate was negatively associated with BMI with $r^{2}$ approaching $2 \%$ (Table 3).
Table 3 Multiple regression models for body mass index as the dependent variable and dietary factors and other non-dietary factors as independent variables in women and men

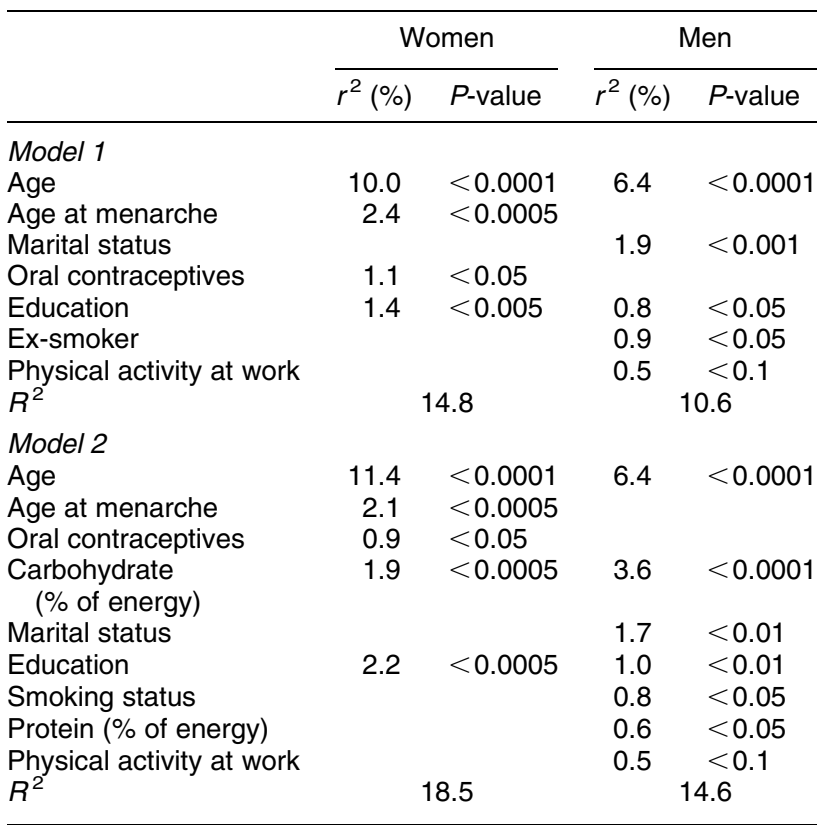

Women - Model 1: age (years), education ( $<$ high school degree, $\geq$ high school degree), age at menarche, parity, menopausal status (yes, no), oral contraceptives (yes, no), hormone replacement therapy (HRT) (yes, no), energy (kJ); Model 2: age (years), education ( $<$ high school degree, $\geq$ high school degree), age at menarche, parity, menopausal status (yes, no), oral contraceptives (yes, no), HRT (yes, no), fat \% of energy, carbohydrate \% of energy, protein $\%$ of energy.

Men - Model 1: age (years), education ( $<$ high school degree, $\geq$ high school degree) smoking status, (current, ex-, non-smoker), marital status (yes), energy (kJ), physical activity at work MET, leisure physical activity; Model 2: age (years), education (<high school degree, $\geq$ high school degree), smoking status, (current, ex-, non-smoker), marital status (yes), fat $\%$ of energy, carbohydrate \% of energy, protein \% of energy, physical activity at work MET, leisure physical activity. 
The first multiple regression model for men included significant socio-economic factors, energy intake, and physical activity at work and at leisure. Age was the strongest explanatory variable but with a rather low coefficient (6.4\%). Other factors were marital status, smoking status, education level and work physical activity, adding up to $R^{2}=10.6 \%$. In model 2 , energy intake was replaced by the percentage of energy provided by each macronutrient as outlined above for women. In this model, $R^{2}$ reached $14.6 \%$ as carbohydrate was negatively associated with BMI with $r^{2}=3.6 \%$ (Table 3). Other models, including ones with separated fatty acids, olive oil and dietary fibre were computed, but none reached a higher $R^{2}$ than model 2 .

Faced with the findings from the multiple linear regression analyses, two explanations were possible. Either the significant factors masked other factors less precisely estimated (e.g. socio-economic factors versus dietary factors) or the relationship of the considered factors to BMI was not linear, i.e. they could be associated differently with overweight and obesity.
We used CFA to investigate these hypotheses (Figs 1 and 2). In women (Fig. 1), axis 1 explained $88.9 \%$ of overweight, which is strongly associated to this axis together with $\geq 50$ years of age, menopause, HRT use and lower level of education. No use of oral contraceptives, parity $\geq 3$ children and energy intake $>10460 \mathrm{~kJ}$ were less tightly associated. Symmetrically, young age, no menopause, higher level of education and use of oral contraceptives were negatively represented on axis 1 . In addition, tobacco use, physical activity at work and white collar/executive occupational status were negatively represented on axis 1 .

Obesity was equally represented on axes 1 and 2, with axis 2 providing $11.1 \%$ of explanation. Young age at menarche (9-11 years) and no occupation were equally represented on both axes, whereas leisure-time physical activity was represented only on axis 2 . A low activity was positively associated and a high activity negatively associated with obesity. The case of the variable 'manual worker' is peculiar in that it was positively associated with overweight but negatively with obesity.

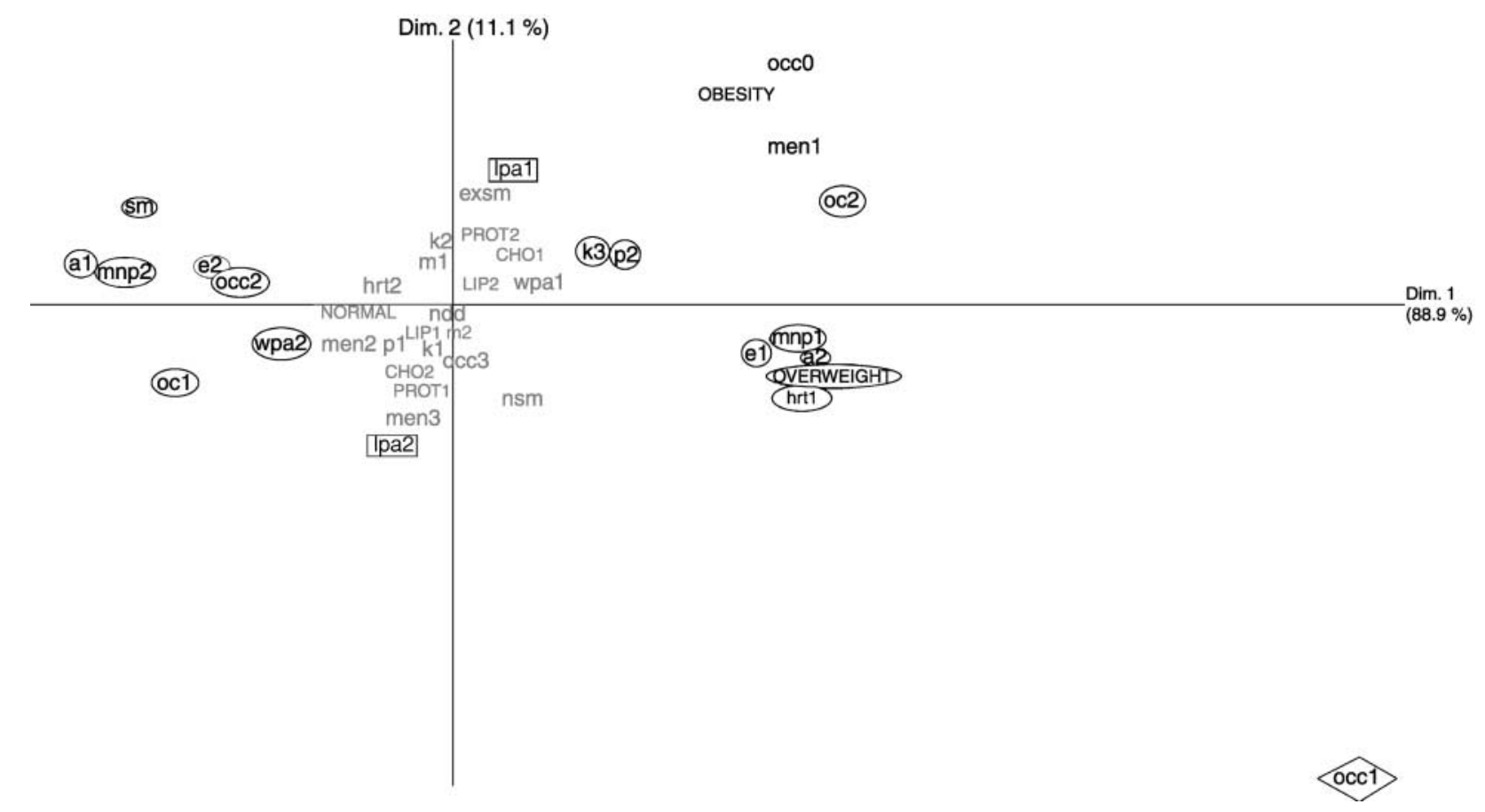

Fig. 1 Correspondence factorial analysis of the relationship between body mass index (BMI) in normal (BMl $<25 \mathrm{~kg} \mathrm{~m}^{-2}$ ), overweight $\left(\mathrm{BMI} \geq 25\right.$ to $<30 \mathrm{~kg} \mathrm{~m}^{-2}$ ) and obese $\left(\mathrm{BMI} \geq 30 \mathrm{~kg} \mathrm{~m}^{-2}\right)$ women and dietary, reproductive life-related and socio-economic variables. Age: a1, 30-49 years; a2, $\geq 50$ years. Occupational status: occ0, none; occ1, manual workers; occ2, white-collar workers and executives; occ3: employees and blue-collar workers. m, marital status. e1, low level of education; e2, high level of education. sm, smoker; exsm, exsmoker; nsm, non-smoker. k1, low energy intake (<8368 kJ); k2, medium energy intake ( $\geq 8368$ to $\leq 10460 \mathrm{~kJ})$; k3, high energy intake $(>10460 \mathrm{~kJ})$. PROT1, $<15.4 \%$ of energy provided by protein; PROT2, $\geq 15.4 \%$ of energy provided by protein. $\mathrm{CHO},<42.5 \%$ of energy provided by carbohydrate; $\mathrm{CHO} 2, \geq 42.5 \%$ of energy provided by carbohydrate. LIP1, $<39.1 \%$ of energy provided by lipids; LIP2, $\geq 39.1 \%$ of energy provided by lipids. wpa1, $<14.7 \mathrm{MET}$ day $^{-1}$ working physical activity; wpa2, $\geq 14.7 \mathrm{MET}_{\text {day }}{ }^{-1}$ working physical activity. Ipa1, $<1.6 \mathrm{MET}_{\text {day }}{ }^{-1}$ leisure physical activity; Ipa2, $\geq 1.6 \mathrm{MET} \mathrm{day}^{-1}$ leisure physical activity. men1, early menarche $(<12$ years); men2, menarche at 11-13 years; men3, menarche at $\geq 14$ years. mnp1: menopause yes; mnp2, menopause no. oc1, oral contraceptives yes; oc2, oral contraceptives no. hrt1, hormone replacement therapy (HRT) yes; hrt2, HRT no. p1, $<3$ children; p2, $\geq 3$ children. No surrounding means an equal representation on both axes; a circle surrounds variables associated with overweight on axis 1; a square surrounds variables associated with obesity on axis 2; and a diamond indicates an association with overweight and obesity of opposite sign for the variable. Values of the representation on the axes are given together with the square cosines in Appendix A; variables in grey have a coefficient $<0.10$ 


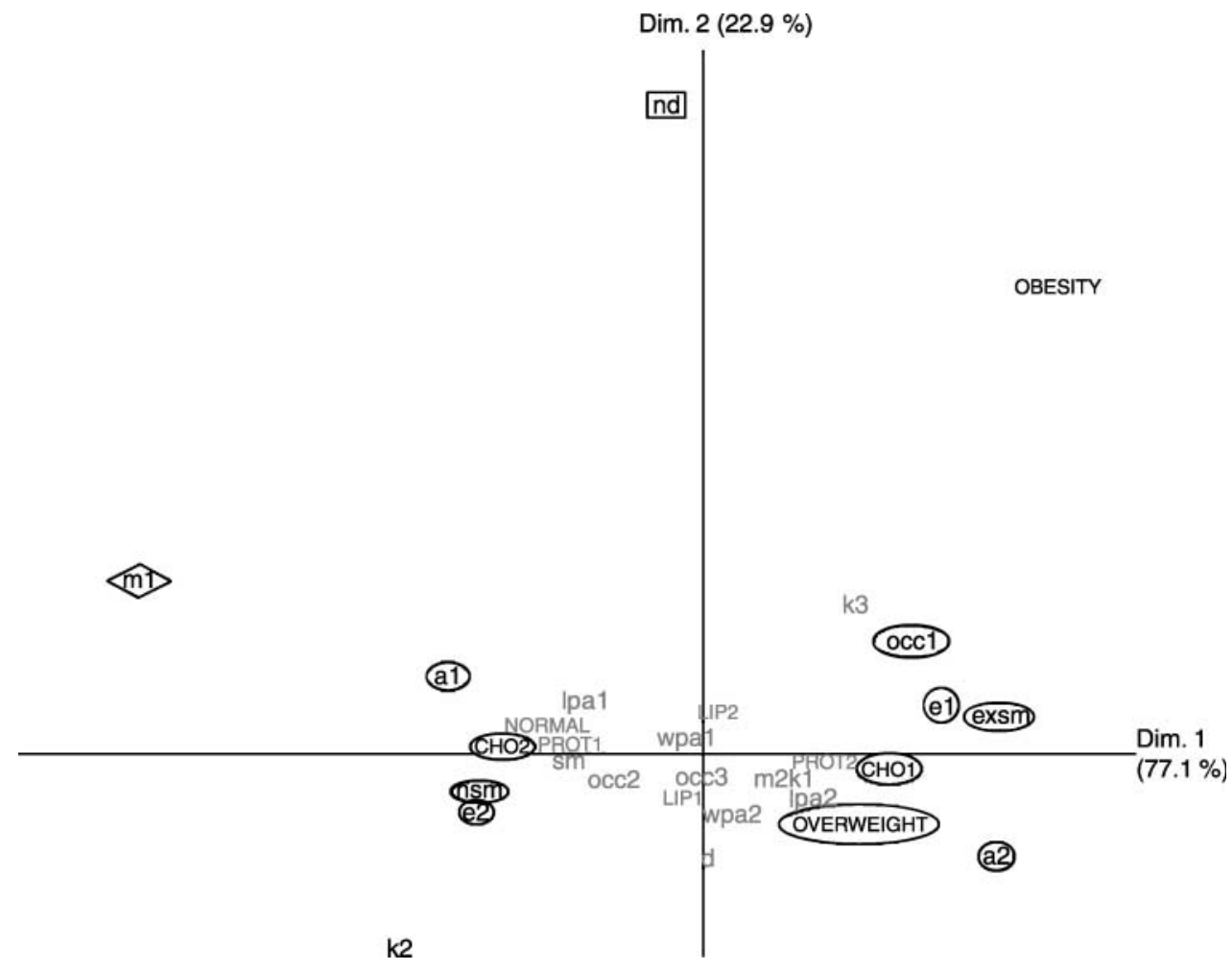

Fig. 2 Correspondence factorial analysis of the relationship between body mass index (BMI) in normal (BMI $<25 \mathrm{~kg} \mathrm{~m}^{-2}$ ), overweight $\left(\mathrm{BMI} \geq 25\right.$ to $<30 \mathrm{~kg} \mathrm{~m}^{-2}$ ) and obese $\left(\mathrm{BMI} \geq 30 \mathrm{~kg} \mathrm{~m}^{-2}\right.$ ) men and dietary and socio-economic variables. Age: a1, $30-49$ years; a2, $\geq 50$ years. Occupational status: occ1, manual workers; occ2, white-collar workers and executives; occ3, employees and blue-collar workers. $\mathrm{m}$, marital status. e1, low level of education; e2, high level of education. sm, smoker; exsm, ex-smoker; nsm: non-smoker. k1, low energy intake (<8368 kJ); k2, medium energy intake ( $\geq 8368$ to $\leq 10460 \mathrm{~kJ})$; $\mathrm{k} 3$, high energy intake ( $>10460 \mathrm{~kJ})$. PROT1, $<14.4 \%$ of energy provided by protein; PROT2, $\geq 14.4 \%$ of energy provided by protein. CHO1, $<42.0 \%$ of energy provided by carbohydrate; $\mathrm{CHO} 2$, $\geq 42.0 \%$ of energy provided by carbohydrate. LIP1, $<37.0 \%$ of energy provided by lipids; LIP2, $\geq 37.0 \%$ of energy provided by lipids. wpa1, $<21.5$ MET day $^{-1}$ working physical activity; wpa2, $\geq 21.5 \mathrm{MET}$ day $^{-1}$ working physical activity. Ipa1, $<2.2$ MET day $^{-1}$ leisure physical activity; Ipa2, $\geq 2.2 \mathrm{MET}_{\text {day }}{ }^{-1}$ leisure physical activity. No surrounding means an equal representation on both axes; a circle surrounds the variables associated with overweight on axis 1; a square surrounds variables associated with obesity on axis 2; and a diamond indicates an association with overweight and obesity of opposite sign for the variable. Values of the representation on the axes are given together with the square cosines in Appendix B found on previous page

In men (Fig. 2), axis 1 was less explicative (77.1\%) and axis 2 more so (22.9\%) than in women. Overweight was better represented on axis 1 , associated with age $\geq 50$ years, a low intake of carbohydrate $(<41.98 \%$ of total energy intake), being an ex-smoker, low level of education and being a manual worker. Hence, young age, being a non-smoker, having a higher level of education and a high intake of carbohydrate $(\geq 41.98 \%)$ were inversely associated with overweight.

Obesity was equally represented on both axes. Being a non-drinker was the only variable associated with axis 2 . An energy intake $<10460 \mathrm{~kJ}$ was negatively associated both with overweight and obesity. Being single was negatively associated with overweight and slightly positively associated with obesity.

\section{Discussion}

With regard to the prevalences of overweight (28.7\%) and obesity (7\%), our results are comparable to those of the French sub-sample of a study ${ }^{21}$ conducted in the
European Union in 1997 on about 1000 subjects (men and women: 24.0 and 5.3\%, respectively), and confirm that the French, together with the Swedes and Italians, have the lowest prevalence of obesity. This supports the validity of our sample. Our study focused on southern France and indicated that obesity prevalence appears to be lower than national levels, whereas overweight prevalence is higher. Our female sample can be compared with the results of the French E3N-EPIC study (European Prospective Investigation into Cancer and Nutrition; F Clavel, personal communication), which showed that women from southern regions had the lowest prevalence of overweight and obesity. However, their findings, based on a cohort comprised mostly of teachers recruited in the same region (Hérault), showed prevalences of overweight (11.4\%) and obesity (2.9\%) even lower than those found in the present study, possibly because their subjects had a higher level of education whereas our sample tends to be representative of the general population. A further study of men and women aged 35-64 years was conducted in Southwest France between 1985 and $1997^{22}$. The prevalences of 
overweight and obesity were $25 \%$ and $11 \%$ in women, and $50 \%$ and $13 \%$ in men, in the years corresponding to those of the MEDHEA study, all percentages being higher than our figures, especially for obesity. However, they observed the same discrepancy between women and men concerning the age when BMI increases: overweight is only $15 \%$ and obesity $4 \%$ in women below 45 years, whereas it is already $45 \%$ and $7 \%$ in men at this age. It should be noted that only $15 \%$ of our sample were recruited from the Southwest region.

Several studies have underlined the importance of socio-economic factors and physical activity either by studying them only ${ }^{21,23,24}$ or by showing their stronger weight in multiple regression analyses that also included dietary variables ${ }^{25}$. All studies reported the positive association of age and lower education with overweight and/or obesity, as we observe in our multiple regression analysis. When stratified for gender in these studies, menopause and parity ( $\geq 3$ children) were associated ${ }^{25}$, and higher socio-economic status inversely associated ${ }^{24}$, with obesity in women, and being an ex-smoker only in men, in line with our results.

In the present study dietary factors were only weakly associated with BMI, and the negative association of carbohydrate intake with BMI appeared to be the only significant dietary factor. Comparable findings were reported by Gonzalez et $a .^{25}$, who showed that carbohydrate intake as a percentage of energy was negatively associated with BMI with a higher $r^{2}$ than fat intake as a percentage of energy (0.3 and 0.04\%, respectively). There are several hypotheses to explain this very loose association between dietary factors and BMI in epidemiological studies. Several epidemiologists $^{26-28}$ are convinced that it is true. However, on the one hand, it contradicts experimental diet studies on volunteers (as reviewed in reference 29) and, on the other, epidemiological studies are flawed with biases. The first of these biases is related to the non-reliability of dietary assessment in obese subjects. In spite of the care taken in the elimination of underreporters, quantitative bias is difficult to avoid ${ }^{30,31}$. The second bias is that these findings are generally based on cross-sectional studies, which prohibits defining a temporal sequence between diet and obesity. Therefore, sociodemographic factors, which are more precisely estimated and more stable over time, override dietary factors within statistical analyses.

Another consideration is that overweight and obesity may be two different entities, which are not represented by the linearity of increasing BMI. In a previous study on this sample, overweight was associated with a good quality dietary index but not obesity ${ }^{11}$. Therefore the variability of each deserves to be analysed separately. A study ${ }^{23}$ conducted with a sample of 515 young Kuwaiti college men with $11 \%$ obesity computed the logistic regression both on overweight and obesity with socioeconomic factors. The author found that being married was a factor significantly associated with overweight and not with obesity in this young sample. In the MEDHEA study the sub-sample of obese subjects was too small to provide robust results in a logistic regression, hence CFA was used to allow for the separate analysis of overweight and obesity on the total samples of women or men. The results indicated that patterns are not the same for overweight and obesity.

For overweight, energy imbalance seems the main factor; there is a high energy intake, which might be aggravated by unbalanced intakes of macronutrients (insufficient carbohydrates). A high energy intake is usual in manual workers and their spouses, and in less educated subjects; it is also generally more common when living as a couple especially for men, as described by $\mathrm{Al}^{-\mathrm{Isa}^{23}}$. It is well known that smokers tend to have lower weights and that ex-smokers gain weight. These factors are grossly similar in both sexes. In women, factors related to reproductive life - menopause, taking HRT but not oral contraceptives and having more than 3 children - are also associated with overweight. This is in line with the sudden rise in overweight prevalence at 50 years of age observed in women, when estimated through 5-year age categories, which suggests a relationship with hormonal changes and/or changes in the psychological attitude of menopausal women towards their shape. These variables may also be confounded by age.

By contrast, the factors related to obesity are much less clearly identified, and they are different between women and men. They are associated with both obesity and overweight, or are specifically related to obesity, or they display opposite relationships with overweight and obesity.

In women, being without occupational activity and menarche occurring at an early age were equally associated with obesity and overweight. Both variables suggest a relationship with diet: the first situation might induce disorders of eating behaviour, and a high-energy diet has been linked to early menarche $\mathrm{e}^{32,33}$. Thus, this is an indication that an energy-rich diet occurring early in adolescence is a factor for overweight and obesity. It is interesting to note that age at menarche decreases by birth cohort from 1930 to $1950^{34}$, together with an increasing rate of obesity prevalence. High leisure-time physical activity is the only factor specifically associated with obesity, as shown by others ${ }^{35}$. In contrast, whereas being a manual worker or a manual worker's spouse is associated with overweight, it is inversely associated with obesity. The MEDHEA study indicated ${ }^{11}$ that manual workers' food habits are characterised by a good quality dietary index, low SFA and cholesterol, and high intakes of fruits, vegetables, fish and olive oil, independently of the quantity. Such a dietary profile, although it might induce overweight if too abundant, may prevent the development of characterised obesity. Thus, some factors associated with obesity are also related to energy balance, but with 
some specific characteristics with regard to intake (unbalanced diet) and age (adolescence).

In men, a low intake of energy was inversely associated with both overweight and obesity. Being a non-drinker is solely associated with obesity. Abstaining from drinking could be the result of a medical recommendation, although it has been shown that light to moderate alcohol consumption has a favourable effect on the metabolic syndrome ${ }^{36}$. Alternatively, in a north Mediterranean region, not drinking wine might indicate either a different cultural origin or difficulty in socialising. Being single is associated with obesity whereas it is inversely associated with overweight. Some difficulties in everyday life with possible difficult social integration and/or the psychological repercussions of being single may favour the development of obesity. Alternatively, being a nondrinker and single might confound an unbalanced diet (wine drinkers had a better diet quality index than did non-drinkers in our region ${ }^{11}$ ) or these two factors might reflect a consequence of being obese and not a determinant. Thus although it is shown that diet and energy imbalance might play a role in obesity development, it should be underlined that there are probably other factors that could not be identified in this study, such as specific psychological behaviours and genetics.

There are two types of limitation that could bias our results on obesity prevalence: one is related to the representativeness of the sample, the other to the behaviour of obese subjects. The small number of positive answers might have selected out underweight or normalweight subjects. The sample was compared with regard to sex and residency distribution with that given by the national institute of statistics (INSEE) for the region under study and found to be similar. Concerning occupational status, the proportions of employees, blue- and whitecollar workers and executives in the study sample were also similar to those given by INSEE, but there were fewer manual workers in our study sample than in the general population of the region under study. Therefore, since it is generally known that obesity is more prevalent in this social class, the under-representation of manual workers in our sample may bias the estimation of obesity prevalence. However, this socio-economic class, as well as the low education class, weighted enough to show that it was associated with overweight in our study. Another limitation related to the representativeness of the sample might result from the use of the electoral list for randomisation, since some people may not be registered. However, young people are generally those who are not registered and since only subjects 30 years old and above were included in the study, this bias is minimised. In addition, the inclusion of more young subjects would have lowered the overweight and obesity prevalence, which is not the actual concern. On the other hand, obese subjects could have cheated on their weight. A question on clothes size in the questionnaire permitted us to double-check the validity of the self-declared weight: the correlation between BMI and clothes size of the subjects was 0.82 . Overweight and obese subjects could have cheated on both weight and clothes size, but it required two deliberate falsifications in front of a feminine interviewer, which seems less likely.

The major strength of our study is the large coverage of sociodemographic and dietary factors elicited by a validated questionnaire that has been used in several published studies ${ }^{8-11,13-15}$ and administered through trained interviewers. Another interesting aspect is the high prevalence of overweight subjects in the sample, mainly in men, which conferred robustness to the findings related to it.

In conclusion, this study suggests that energy imbalance induced by various lifestyle factors plays a major role in the development of overweight whereas obesity represents a more complex entity. Thus, from the perspective of public health policy, it appears useful to (1) develop quantitative and qualitative knowledge about nutrition in the general population, (2) facilitate the development of inexpensive food of good nutritional quality (e.g. processed food, breeding farms for fish) and (3) develop and enhance access to leisure physical activity and sport, especially for adult women. On an individual level, it appears necessary to adapt counselling and recommendations to overweight and obesity, respectively, and in each category also to age, gender, marital status, lifestyle (smoking, drinking, dietary habits, physical exercise) and economic/psychological status.

\section{Acknowledgements}

The authors gratefully acknowledge the help of Michelle Holdsworth and Monique Romon for valuable discussions; of Marie-Hélène Avallone for the interviews; and the financial support of the Ligue contre le Cancer (Hérault) and the Regional Council of Languedoc-Roussillon.

\section{References}

1 World Health Organization (WHO). Prevention and Management of the Global Epidemic of Obesity. Report of the WHO Consultation on Obesity. Geneva: WHO, 1998.

2 Beer-Bost S, Morabia A, Hercberg S, Vitek O, Bernstein MS, Galan P, et al. Obesity and other health determinants across Europe: The EURALIM Project. Journal of Epidemiology and Community Health 2000; 54: 424-30.

3 Molarius A, Seidell JC, Sans S, Tuomilehto J, Kuulasmaa K. Varying sensitivity of waist action levels to identify subjects with overweight or obesity in 19 populations of the WHO MONICA Project. Journal of Clinical Epidemiology 1999; 52 1213-24.

4 Kürzinger ML, Salem G, Rican S, Rey J-L. Disparités géographiques du surpoids et de l'obésité chez les jeunes hommes en France: 1987-1996. Cabier de Nutrition et de Drététique 2002; 37: 110-7.

5 Gerber M. Obésité, l'épidémie. La Recherche 2000; 332 $112-3$. 
6 Seidell JC. Time trends in obesity: an epidemiological perspective. Hormone and Metabolic Research 1997; 29: $155-8$.

7 Riboli E, Decloître F, Collet-Ribbing C, eds. Alimentation et cancer. Evaluaton des données scientifiques. Paris: Tec \& Doc Lavoisier, 1996.

8 Gerber M, Scali J, Avallone MH, Teisson C. MEDHEA: a nutritional survey in Mediterranean countries. First results in Département de l'Hérault, France. Reproduction, Nutrition, Development 1997; 7: 345-6.

9 Gerber M, Siari S, Michaud A, Scali J. Alimentation méditerranéenne et santé. MEDHEA, les résultats de l'Hérault. Actualités en Diététique 1999; 35: 1391-6.

10 Gerber M, Scali J, Michaud A, Durand M, Astre C, Dallongeville J, et al. Profiles of a healthful diet and its relationship to biomarkers in a population sample from Mediterranean southern France. Journal of the American Dietetic Association 2000; 100: 1164-71.

11 Scali J, Richard A, Gerber M. Diet profiles in a population sample from Mediterranean southern France. Public Health Nutrition 2001; 4: 173-82.

12 Ainsworth BE, Haskell WL, Leon AS, Jacobs DR Jr, Montoye HJ, Sallis JF, et al. Compendium of physical activities: classification of energy costs of human physical activities. Medicine and Science in Sports and Exercise 1993; 25: $71-80$.

13 Bonifacj C, Gerber M, Scali J, Daurès JP. Comparison of dietary assessment methods in a Southern French population: use of weighed records, estimated-diet records and a food-frequency questionnaire. European Journal of Clinical Nutrition 1997; 51: 217-31.

14 Gerber M, Romon M, Scali J, Dallongeville J, Astre C. Erythrocyte fatty acids as markers of dietary fatty acids and relevant food intake. European Journal of Clinical Nutrition 1998; 52: S62

15 Daurès JP, Gerber M, Scali J, Astre C, Bonifacj C, Kaaks R. Validation of a food-frequency questionnaire using multipleday records and biochemical markers: application of the triads method. Journal of Epidemiology and Biostatistics 2000; 5: 109-15.

16 Ford ES, Merritt RK, Heath GW, Powell KE, Washburn RA, Kriska A, et al. Physical activity behaviors in lower and higher socio-economic status populations. American Journal of Epidemiology 1991; 133: 1246-56.

17 Caspersen CJ, Bloemberg BPM, Saris WHM. The prevalence of selected physical activities and their relation with coronary heart disease risk factors in elderly men: the Zutphen study. American Journal of Epidemiology 1991; 133: 1078-92.

18 Wannmethee A, Shaper AG, Macfarlane PW. Heart rate, physical activity, and mortality from cancer and other noncardiovascular diseases. American Journal of Epidemiology 1993; 137: 735-48.

19 Falkner KL, Trevisan M, McCann SE. Reliability of recall of physical activity in the distant past. American Journal of Epidemiology 1999; 150: 195-205.

20 Garcia-Acosta S, Clavel-Chapelon F. Gestion des données manquantes, aberrantes et incohérentes dans l'étude de cohorte E3N. Revue d'Epidemiologie et de Santé Publique 1999; 47: 515-23.

21 Martinez JA, Kearney JM, Kafatos A, Paquet S, MartinezGonzalez MA. Variables independently associated with selfreported obesity in the European Union. Public Health Nutrition 1999; 2: 125-33.

22 Marques-Vidal P, Ruidavets JB, Cambou JP, Ferrieres J. Trends in overweight and obesity in middle-aged subjects from Southwestern France. International Journal of Obesity and Related Metabolic Disorders 2002; 26: 732-4.

23 AI-Isa AN. Dietary and socio-economic factors associated with obesity among Kuwaiti college men. British Journal of Nutrition 1999; 82: 369-74

24 Wardle J, Waller J, Jarvis MJ. Sex differences in the association of socioeconomic status with obesity. American Journal of Public Health 2002; 92: 1299-304.

25 Gonzalez CA, Pera G, Quiros JR, Lasheras C, Tormo MJ, Rodriguez M, et al. Types of fat intake and body mass index in a Mediterranean country. Public Health Nutrition 2000; 3: 329-36.

26 Willett WC. Dietary fat plays a major role in obesity: no. Obesity Reviews 2002; 3: 59-68.

27 Willett WC. Dietary fat and obesity: an unconvincing relation. American Journal of Clinical Nutrition 1998; 68 : 1149-50.

28 Knopp RH, Walden CE, Retzlaff BM, McCann BS, Dowdy AA, Albers JJ, et al. Long-term cholesterol-lowering effects of 4 fat-restricted diets in hypercholesterolemic and combined hyperlipidemic men. The Dietary Alternatives Study. Journal of the American Medical Association 1997; 278: 1509-15.

29 Bray GA, Popkin BM. Dietary fat intake does affect obesity! American Journal of Clinical Nutrition 1998; 68: 1157-73.

30 Goris AHC, Westerterp-Plantenga MS, Westerterp KR. Undereating and underrecording of habitual food intake in obese men: selective underreporting of fat intake. American Journal of Clinical Nutrition 2000; 71: 130-4.

31 Braam LAJLM, Ocké MC, Bueno-de-Mesquita HB, Seidell JC. Determinants of obesity-related underreporting of energy intake. American Journal of Epidemiology 1998; 147: 1081-6.

32 Stoll BA. Western diet, early puberty, and breast cancer risk. Breast Cancer Research and Treatment 1998; 49: 187-93.

33 Berkey CS, Gardner J, Frazier AL, Colditz GA. Relation of childhood diet and body size to menarche and adolescent growth in girls. American Journal of Epidemiology 2000; 152: 446-52.

34 Clavel-Chapelon $\mathrm{F}$ and the E3N-EPIC Group. Evolution of age at menarche and at onset of regular cycling in a large cohort of French women. Human Reproduction 2002; 1: $101-5$.

35 Martinez-Gonzalez MA, Martinez JA, Hu FB, Gibney MJ, Kearney J. Physical inactivity, sedentarism, lifestyle and obesity in the European Union. International Journal of Obesity 1999; 2: 1192-201.

36 Dixon JB, Dixon ME, O’Brien PE. Alcohol consumption in the severely obese: relationship with the metabolic syndrome. Obesity Research 2002; 10: 245-52. 
Appendix A - Values of coefficients on the axes and square cosines of the correspondence factorial analysis (women)

\begin{tabular}{|c|c|c|c|c|c|c|}
\hline & \multicolumn{3}{|c|}{ Dimension 1} & \multicolumn{3}{|c|}{ Dimension 2} \\
\hline & + & - & $\cos ^{2}$ & + & - & $\cos ^{2}$ \\
\hline Overweight & 0.27 & & 0.97 & & & \\
\hline Obesity & 0.18 & & 0.52 & 0.17 & & 0.48 \\
\hline occ1 & 0.65 & & 0.79 & & -0.33 & 0.21 \\
\hline oc2 & 0.28 & & 0.93 & & & \\
\hline a1 & & -0.26 & 0.99 & & & \\
\hline a2 & 0.26 & & 0.99 & & & \\
\hline hrt1 & 0.25 & & 0.94 & & & \\
\hline mnp1 & 0.25 & & 0.99 & & & \\
\hline mnp2 & & -0.23 & 0.99 & & & \\
\hline $\mathrm{sm}$ & & -0.22 & 0.91 & & & \\
\hline men1 & 0.22 & & 0.75 & 0.13 & & 0.25 \\
\hline occ0 & 0.22 & & 0.58 & 0.19 & & 0.42 \\
\hline e1 & 0.22 & & 0.98 & & & \\
\hline oc1 & & -0.20 & 0.93 & & & \\
\hline e2 & & -0.17 & 0.98 & & & \\
\hline occ2 & & -0.15 & 0.98 & & & \\
\hline wpa2 & & -0.12 & 0.96 & & & \\
\hline p2 & 0.12 & & 0.91 & & & \\
\hline k3 & 0.10 & & 0.86 & & & \\
\hline Ipa1 & & & 0.17 & 0.10 & & 0.83 \\
\hline Ipa2 & & & 0.17 & & -0.10 & 0.83 \\
\hline
\end{tabular}

Appendix B - Values of coefficients on the axes and square cosines of the correspondence factorial analysis (men)

\begin{tabular}{|c|c|c|c|c|c|c|}
\hline & \multicolumn{3}{|c|}{ Dimension 1} & \multicolumn{3}{|c|}{ Dimension 2} \\
\hline & + & - & $\cos ^{2}$ & + & - & $\cos ^{2}$ \\
\hline Obesity & 0.22 & & 0.47 & 0.23 & & 0.53 \\
\hline Overweight & 0.09 & & 0.85 & & & \\
\hline $\mathrm{m} 1$ & & -0.33 & 0.91 & 0.10 & & 0.09 \\
\hline $\mathrm{k} 2$ & & -0.19 & 0.75 & & -0.11 & 0.25 \\
\hline exsm & 0.18 & & 0.98 & & & \\
\hline a1 & & -0.15 & 0.90 & & & \\
\hline a2 & 0.17 & & 0.90 & & & \\
\hline e1 & 0.14 & & 0.96 & & & \\
\hline $\mathrm{nsm}$ & & -0.13 & 0.97 & & & \\
\hline e2 & & -0.13 & 0.96 & & & \\
\hline occ1 & 0.13 & & 0.77 & & & \\
\hline $\mathrm{CHO} 2$ & & -0.11 & 1.00 & & & \\
\hline $\mathrm{CHO} 1$ & 0.11 & & 1.00 & & & \\
\hline nd & & & & 0.38 & & 1.00 \\
\hline
\end{tabular}

